\title{
KEEPING EVERYONE ON THE SAME PAGE DURING FLASH FLOOD EMERGENCIES
}

\author{
BAXTER E. VIEUX \& JEAN E. VIEUX \\ Vieux \& Associates, Inc., Oklahoma, USA
}

\begin{abstract}
Emergency managers need to know when and where flooding is likely to occur to effectively respond to hazards. Understanding flood risk is aided by the use of a common operating picture (COP) that helps keep everyone on the same page during a flood emergency. Emergency response is aided by bringing together diverse information including distribution of rainfall and predicted flood inundation. The complexity of information sources that can benefit flood management decisions requires thoughtful integration and management. Knowing where and when a stream is likely to overtop its banks, or if road intersections are forecast to flood, makes advanced actions possible and helps protect citizens and property. Public flood warnings are generally the responsibility of national water management, or weather forecasting agencies. However, flood forecasting information services are increasingly being developed for and by municipalities, flood control districts, or private entities requiring more specificity of location, timeframe, and type of flood information. A gap analysis of a flood warning system after a major flood resulted in the development of a COP as a cloud-hosted web application. The results presented demonstrate effectiveness of the COP, which is an integrated system that supports many aspects of an early warning system used internally by agencies responsible for emergency management. Keywords: floods, forecasting, decision support, computer information systems, cloud-based integration, emergency management, operational dashboard, real-time data, common operating picture.
\end{abstract}

\section{INTRODUCTION}

Occurrences of heavy rainfall and flood events are increasingly impacting people and infrastructure, especially as urban development encroaches into floodplains [1], [2]. Ahmadalipour and Moradkhani [2] analyzed flash flood occurrence from 1996-2017 and found that $99 \%$ of flash floods in the continental US (CONUS) occur due to combination of rain on burned area, rain on snow, tropical storm, or generally heavy rainfall. Texas, Oklahoma, and Arizona were identified as the top flashflood prone states in their analysis, with frequent events and abundant casualties. Climate change has affected the number of flashflood events, increasing by $1 \%$ over the 22 -year period studied by Ahmadalipour and Moradkhani [2]. They found that total property damages caused by flashfloods also exhibited a significant positive trend in the past 22 years. Occurring in 2017 along the Texas Gulf Coast, Hurricane Harvey topped all other flash floods in terms of property damage within the period studied. Global recognition to reduce disasters of all causes is represented by the Sendai Framework for Disaster Risk Reduction (SFDRR) adopted by signatory states in 2015 [3]. The SFDRR establishes targets for signatory states to accomplish disaster reduction including: "Substantially increase the availability of and access to multi-hazard early warning systems and disaster risk information and assessments to the people by 2030 ". Thus, an early warning system (EWS) is recognized globally as an important tool for disaster reduction.

An EWS has the potential to save lives particularly if the warnings are effectively communicated to vulnerable populations [4], which is also reported by Terti et al. [5] in the US. Perhaps typical of the US, they found a high number of fatalities associated with being in a vehicle. Further, the number of fatalities depends on the time of day, nighttime flash floods produce more fatalities than in the daytime [2], [5]. These factors related to flood 
vulnerability and social science aspects emphasize the importance of the human dimension when designing flood risk communication that reaches the most vulnerable. This need is predicated on the target audience of the EWS, whether it is public facing or for internal agency use. Considering the public's perception requires adding a social science dimension to create an effective warning system [6]. Public facing systems can suffer from ineffective communications, either because the public did not take appropriate actions, did not perceive, understand or trust the warning information, or because they never received the warning in a timely manner or at all (see for example the survey results after the 2013 Front Range Flood in Colorado, US by [7]).

At the local level there are several examples of EWS setup and operations by local organizations such as municipalities for internal use in coordination of emergency response for the City of Austin, Texas flood early warning system [8]. Operational inundation mapping is becoming more important because of its value in communicating risk for emergency response as described by Greene et al. [9]. Thielen et al. [10] describe the development of the European Flood Alert System (EFAS), which aims at increasing preparedness for floods in trans-national European river basins. At the national level, flood forecasting systems have been deployed such as SCHAPI in France [11], ISOK in Poland [12], in Barcelona, Spain [13], in Germany [14], and in Western Puerto Rico US [15]. The United States National Weather Service (USNWS) has been deployed the National Water Model (NWP) for the CONUS. This ambitious project relies on hydrometeorological forecasts as input to a physics-based model WRF-Hydro [16]. Forecasts are produced for 2.7 million stream segments, with many basins that have not benefitted from model calibration, or where flood control reservoirs are only beginning to be modeled and are not yet operational [17].

Parker [4] identified barriers that may limit the effectiveness of flood warnings and appropriate warning include: (1) translating technical flood forecasts into warnings that are readily understandable by the public; (2) taking legal responsibility for warnings and their dissemination; (3) raising flood-risk awareness; (4) designing effective flood warning messages; (5) knowing how best and when to communicate warnings; and (6) addressing uncertainties surrounding flood warnings. While there have been advances in computer modelling and mapping of flood events, accurate forecasting of surface-water floods can exceed technical or modelling capabilities. Simpler approaches to an EWS can consist of a network of sensors, such as rain gauges and stream level sensors, and some that employ weather radar (see [18], [19]).

As frequently observed, uncertainty can plague hydrologic forecasting especially if physical processes are not well captured in the model structure, such as subsurface runoff. Bandaragoda et al. [20] and Beven [21] observed that hydrologic prediction of subsurface runoff processes can become intractable at the catchment scale. Two principal reasons are: (1) the unknown a-prior value and distribution of parameters controlling shallow water table or aquifer properties that are not well understood; or (2) hydrometeorological forcings, precipitation or snow melt, may not be adequately characterized over the catchment [21]. Excellent hydrologic prediction accuracy from operational distributed modelling was found by Looper and Vieux [22] in urban and peri-urban basins during Tropical Storm Hermine (2010) in Central Texas, US. Analysis of operational results that did not involve adjustment during this extreme event revealed the accuracy associated with two hydrometeorological forcings: (1) gauge adjusted radar rainfall (GARR); and (2) a gauge-only network. To gain equivalent accuracy to that obtained with GARR, the gauge network, though relatively dense, would require further densification. Further analyzes concerning physics-based distributed modelling utilizing weather radar inputs may be found in [23]-[26]. While uncertainty in hydrologic forecasts is unavoidable, incorporating uncertainty as a part of the forecast 
information has met with limited success. Berthet et al. [27] describe an assessment of incorporating uncertainty measures communicated as part of the forecast information but found only limited acceptance among governmental flood forecasting centers and hydroelectricity suppliers because of potential confusion associated with the uncertainty bounds communicated. Vieux [28] describe case studies involving forecast uncertainty in real-time hydrologic forecasting of reservoir inflows to hydroelectric facility with gated dam operations. The operators later declined receiving $20 \%, 50 \%, 80 \%$ uncertainty bounds in favor a single forecast representing the $50 \%$ forecast precipitation as input to the hydrologic forecast of reservoir inflows over a forecast horizon of 3-7 days.

Modern approaches to mitigating flood impacts include information technology embodied by an EWS, sometimes alone or in addition to physical flood control works such as dams, levees, detention ponds, or channel improvements. In the case where pluvial flooding is the main focus, an EWS characteristically contains (1) hydrometeorological input; (2) hydrologic and hydraulic modelling; (3) warnings communicated via text messaging, email, direct phone calls; and (4) inundation mapping that may include damage estimates [4]. One approach to reducing impacts from flooding is to minimize the public's exposure by closing flooded intersections, and warning stakeholders in the affected basins. Emergency responders benefit from knowing when and where flooding is likely to occur, so that effective flood response services can be delivered. Increasingly, an EWS is used to deliver critical flood information in real-time via a dashboard containing essential flood and rainfall-runoff information (additional details in [8]).

Recent EWS technological innovations leverage cloud-based integration of model-based predictive stream flow, rain gauge and radar rainfall, computer-aided dispatch, tweets, highresolution physics-based flood forecast flow and stage, and predictive inundation mapping [1]. Detailed flood inundation mapping helps focus emergency response to areas where a flood is expected, helping to communicate risk within internal agency operations. The following sections provide an overview of the common operating picture (COP) concept, and description of key elements implemented to provide a cloud-based system that aids in decision-making during flood emergencies.

\section{METHODOLOGY}

A gap analysis was performed to develop design objectives of a COP for use by a municipality for internal agency coordination and operations management. The use case is to provide decision support for where to position barricade crews, make highwater rescues, and prepositioning of assets. The following objectives and solutions provide a systematic approach taken in its design with resulting web-application pages shown that are now in operational use. Table 1 summarizes gaps identified that were identified by the agency regarding an existing flood management system, and solutions identified for improvement and implementation as a COP flood management system. The existing system was operational during a major flood in 2013 in Central Texas USA, when the municipality experienced need for improving technology to aid their emergency operations. For each Gap (1-4) identified, a corresponding Solution (1-4) is presented in the sections that follow.

\subsection{Display timeframe}

To satisfy Gap 1, the solution past, present and future timeframes are useful so that replay can show storm and flood evolution leading to the present or current conditions. Future precipitation forecasts when added to current rainfall extends available lead-time before flooding reaches or exceeds threshold values of depth and flow as shown in Fig. 1. 
Table 1: Gap analysis identifying needs and solutions for development of the COP.

\begin{tabular}{|c|c|}
\hline Objective & Solution \\
\hline $\begin{array}{l}\text { Gap 1: The current system did not support } \\
\text { replay or easily support knowing where and } \\
\text { when flooding was occurring. It was not } \\
\text { integrated causing staff to not have access } \\
\text { to crucial information (e.g. geo-located } \\
\text { flood reports) or must rely on multiple } \\
\text { computer system display screens. }\end{array}$ & $\begin{array}{l}\text { - Solution 1: Display timeframe. The } \\
\text { system needs to display: } \\
\text { - Forecast (maximum) flood depth } \\
\text { - Current inundation and road closures } \\
\text { - Future locations of flooded roads and } \\
\text { streams }\end{array}$ \\
\hline $\begin{array}{l}\text { Gap 2: Needed data sources which were } \\
\text { not integrated or available during } \\
\text { emergency operations centre activation. }\end{array}$ & $\begin{array}{l}\text { Solution 2: Diverse data source } \\
\text { integration. Integration of tweets and } 311 \\
\text { calls from multiple computer systems. }\end{array}$ \\
\hline $\begin{array}{l}\text { Gap 3: Corporate knowledge was not } \\
\text { integrated into the system such as how } \\
\text { upstream flood depths could affect } \\
\text { downstream out-of-bank flooding, road } \\
\text { closures, or structure flooding. }\end{array}$ & $\begin{array}{l}\text { Solution 3: Rules engine. Ability to write } \\
\text { rules that affect system operation: } \\
\text { - User can add and modify rules based } \\
\text { on modelled/observed flood levels } \\
\text { - "What-if" functionality } \\
\text { - Automated alert notifications }\end{array}$ \\
\hline $\begin{array}{l}\text { Gap 4: After-action reporting was not } \\
\text { supported by the system for upper } \\
\text { management briefing, storm report, or flood } \\
\text { damage assessment. }\end{array}$ & $\begin{array}{l}\text { Solution 4: Automated reports. After- } \\
\text { action reports will provide summaries of } \\
\text { rainfall storm totals, structures flooded, } \\
\text { road closures, low water crossing device } \\
\text { activation, and inundation polygons. }\end{array}$ \\
\hline
\end{tabular}

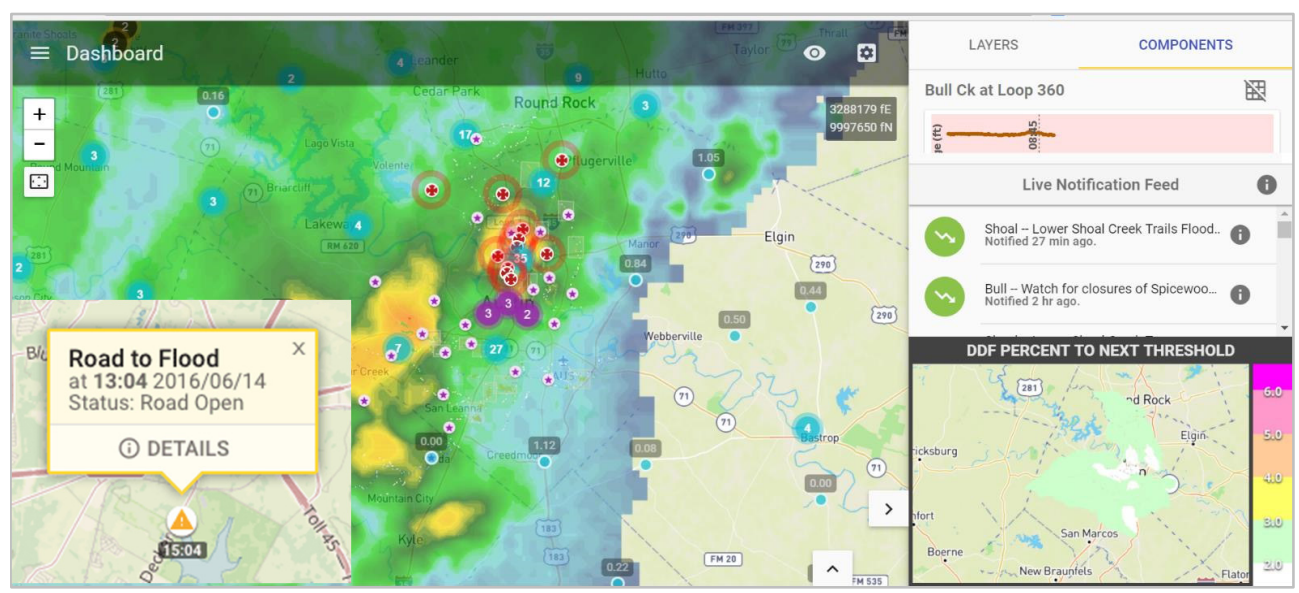

Figure 1: Real-time dashboard with map display of current radar rainfall (map background) with tweets/alerts indicated by icons in map (red cross with pulsating circles), road to flood (bottom left) countdown timer with 13:04 minutes left, forecast and observed hydrographs (top right) with alert log shown with green circles and arrows indicating stage direction (up/down), bottom right shows map of depth duration frequency (light green watersheds $<2$ years). 


\subsection{Diverse data source integration}

There is a diversity of data sources that can be useful during a flood emergency but require integration from other computer systems. Fig. 2 presents a conceptualization of tweets and citizens flood "complaints" (referred to as 311 calls) (left panel), map display of icons and flooding (centre), and a "feed" of notifications as they are produced last-on-top (right).

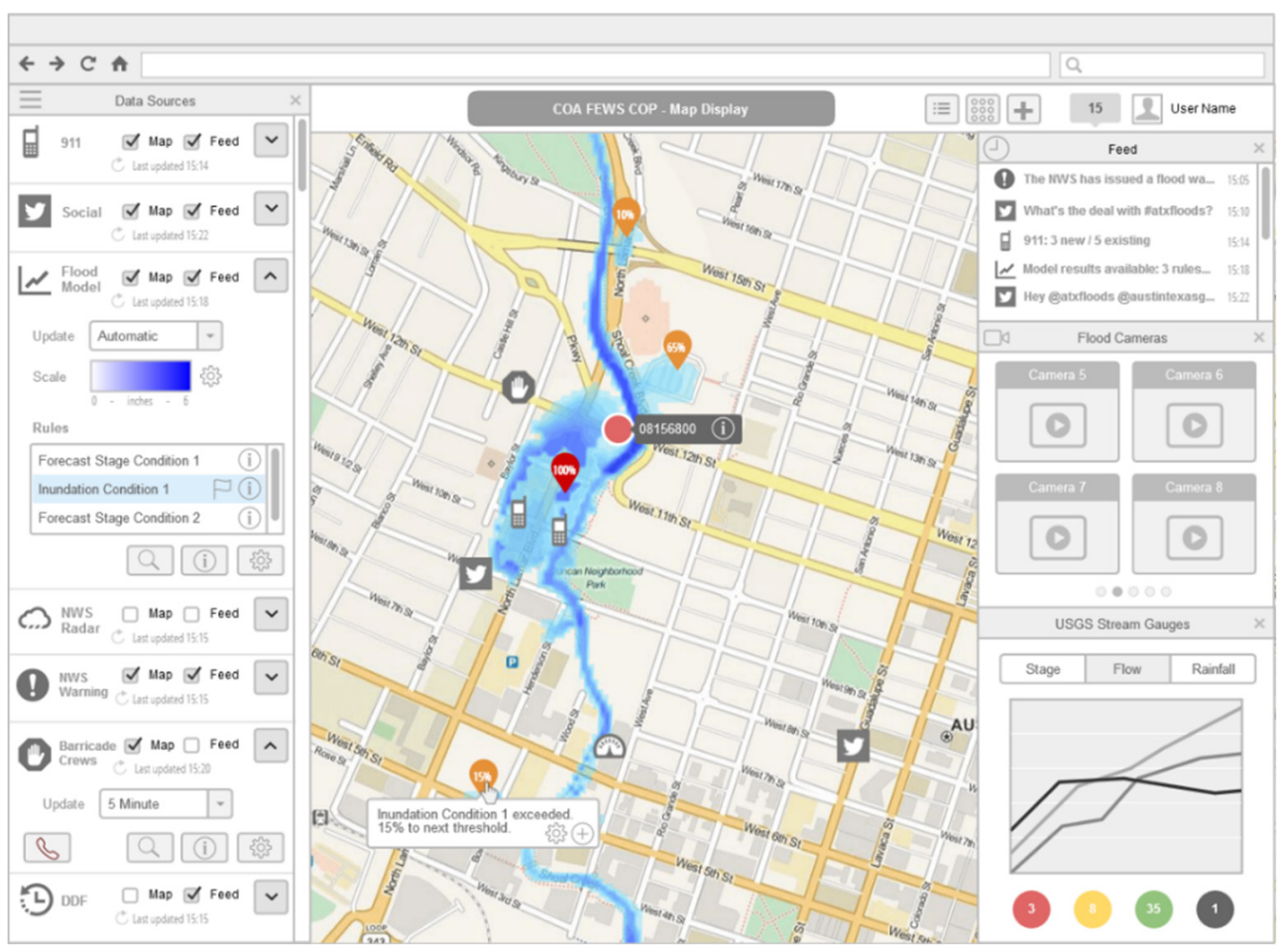

Figure 2: Map view showing integration of data elements (Barricades/311 calls/Tweets/ Streamgauge) and display configuration.

\subsection{Rules manager}

This element provides the user with the ability to write and save rules that affect system operation. For example, the user could add or modify rules based on modelled/observed flood levels, causing an automated alert notification to appear as a flashing map icon or as a notification that a threshold has been exceeded. Fig. 3 shows the control configuration used to set the Data Source (observed or simulated stage), Location (stream gauge), Rule Type (stage threshold) and its value, together with Notifications desired such as "Flag on Map", "Show in Feed", "Send Email/MMS", and the type of "Map Icon".

\subsection{Automated reports}

Automated reporting supports generation of reports after a flood emergency. Both spatial and tabular information contained in the database is extracted and formatted as an editable 


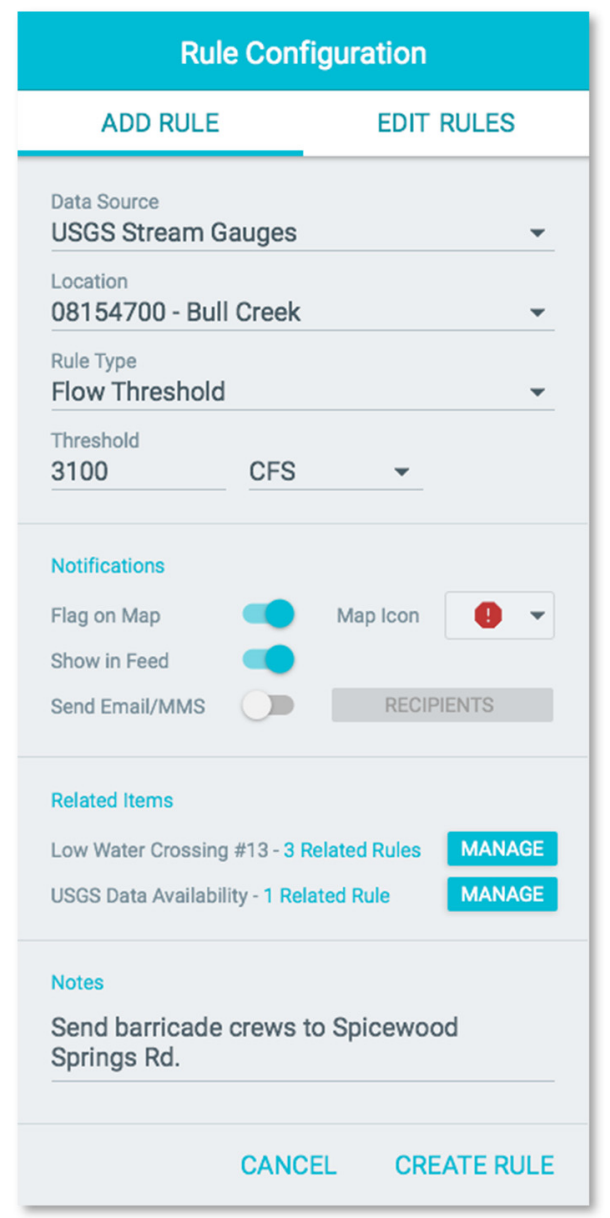

Figure 3: Rules engine allows configuration: Adding/editing/writing rules for system operation. Data source, threshold, and notifications are shown with notes on where to send barricade crews.

document. Report content includes tabular data summaries that include road closures, rules triggered, and structure inundation with preliminary damage estimates. Fig. 4 shows a rainfall total based on weather radar and rain gauge measurement, accumulating $500 \mathrm{~mm}$ over several days. The gridded maps were produced in real-time with rain gauge measurements to correct bias (filled circles), called gauge-adjusted radar rainfall.

\subsection{Cloud-hosting}

A key system characteristic of the COP is integration of multiple data sources. Because integration was identified as a gap, cloud-hosting became necessary and advantageous solution. This design makes possible the integration of real-time predictive flood information data sources, while maintaining user access during periods of high usage, such as flood emergencies. 


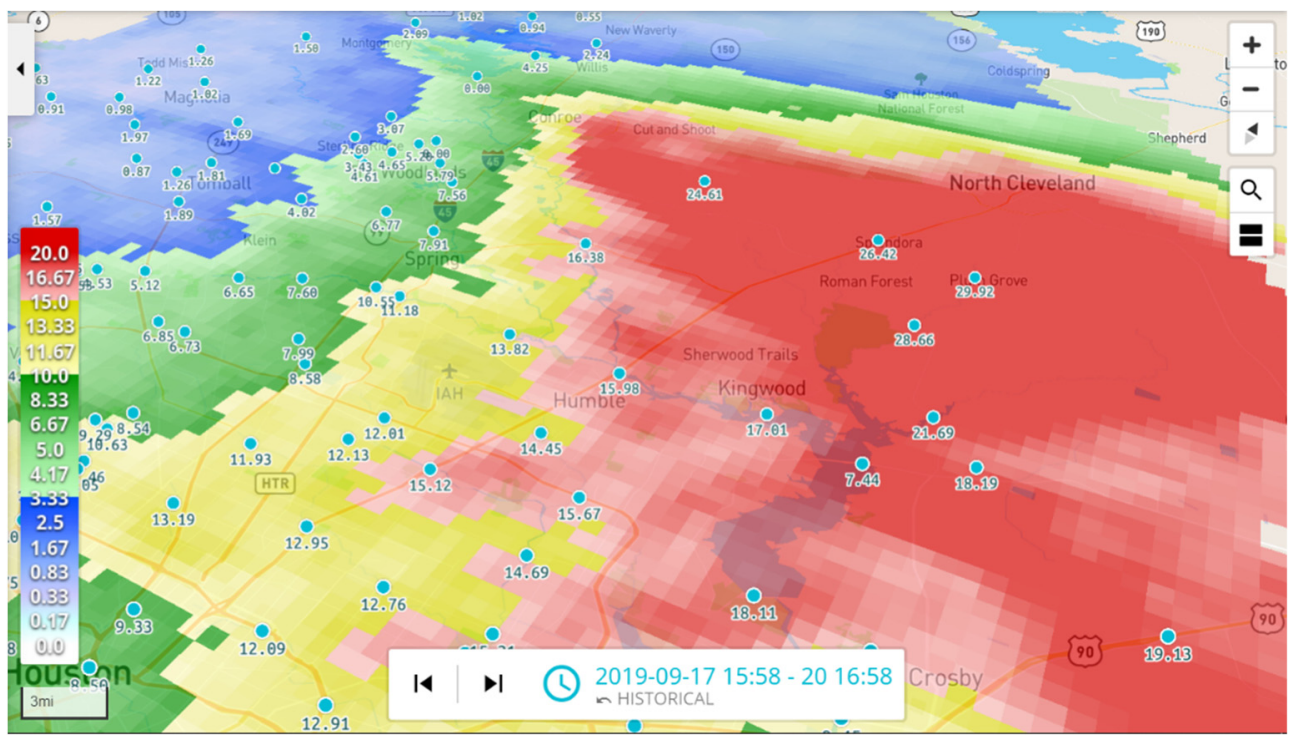

Figure 4: Automated report of a storm total greater than $500 \mathrm{~mm}(1 \mathrm{inch}=25.4 \mathrm{~mm})$.

\section{RESULTS}

Illustrative examples of system performance are presented as follows from the COP and several other EWS's that rely on bespoke radar rainfall systems as input to a physics-based distributed model, $\mathrm{V} f l o^{\circledR}[8]$ that is operational for multiple organizations. Fig. 5: shows two hydrographs for Brays Bayou (256 $\mathrm{km}^{2}$ drainage area) at Main Street (bottom) and upstream at Gessner (top) with a $135.9 \mathrm{~km}^{2}$ drainage area. The operational results are not adjusted in real-time and. The model shows excellent agreement (observed shown as dark red points) from its starting stage on 25 August to 27 August 2017 during beginning portions of Hurricane Harvey which lasted nearly 5 days over Houston Texas. The vertical line is the "now line" at 21:45 CDT on 26 August indicates the time of current rainfall. It is interesting to note that these two stream gauges peak at nearly the same time due to the shape of the watershed. The forecast hydrograph (dark blue) is coincident with observed. At Gessner, the forecast hydrograph is aligned with initial rise in observed. The observed stops short of the "now line" with the last observation, lagging about 1 hour. Lead-time is demonstrated by observing that the forecast peak just under flood stage at Gessner and above flood stage (warning with red shading and watch with yellow). Emergency action and awareness is achieved almost an hour before the flood arrives. Lead-time is closely tied with the location of intense rainfall in a watershed relative to the forecast stream gauge or location. In the case of Harvey, an intense band of rainfall was traveling downstream in the watershed, and with intensification just above the Main Street location, little hydraulic lead-time (less than 1 hour) was achieved. Consequently, hydrologic forecasts based on current rainfall (dark blue) and forecast rainfall (yellow) show little departure after the "now-line" until several hours later as evidenced by the second peak that follows after the first.

Another municipal system, located in Central Texas, also organizes its flood warning operations around an EWS composed of GARR and forecast rainfall from numerical weather prediction and nowcasting [8]. Operational flood emergency management and response is coordinated with the aid of a COP described above in the gap analysis. From forecast 


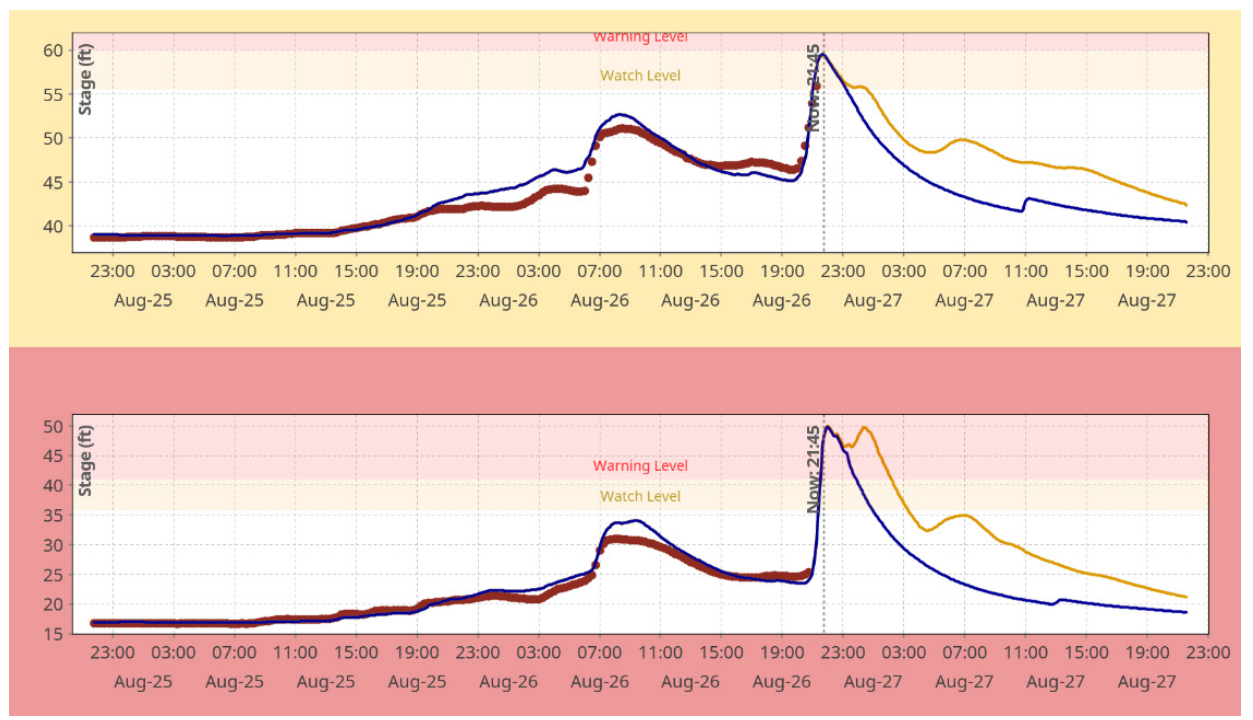

Figure 5: Operational forecast model results showing agreement between observed hydrographs (dark red points) and forecast hydrographs based on current and forecast rainfall (yellow) 25-27 August 2017 during Hurricane Harvey in Houston, Texas $(1 \mathrm{ft}=0.3048 \mathrm{~m}$ referenced to mean sea level $)$.

locations are entered into the Rules Manager based on modelled or observed hydrograph upstream to alert staff of anticipated downstream impacts. For example, at an upstream location, if forecast and/or observed stage exceeds a given threshold, then downstream street intersections are barricaded. This alert notification captures user experiences and integrates it within the system for future use, thus capturing institutional knowledge. There are 166 such rules entered into the system by operational flood staff to assist operations during flood emergencies. Fig. 6 shows the results of Hurricane Harvey after it travelled inland from the Gulf Coast. Its strength was considerably diminished but still produced flooding above flood stage watch and warning levels at $4 \mathrm{ft}(1.2 \mathrm{~m})$ and $5 \mathrm{ft}(1.5 \mathrm{~m})$, respectively over a prolonged period of several days in an urbanizing watershed comprising only $5.6 \mathrm{~km}^{2}$ drainage area. Rainfall accuracy and relatively impervious soils modelled with hydraulics derived from $5 \mathrm{~m}$ resolution gridded elevation data produce exceptionally accurate forecast stage, again without a forecaster in the loop adjusting the model during or after operations. Results shown are "as-is" obtained during operations during Hurricane Harvey. The dark red points indicate observed stage while the green hydrograph is simulated with a USNWS weather radar (NEXRAD) product called DPR which relies on radar with dual polarization to estimate rainfall intensities [19], [28]. This product is independent of the local organization's rain gauge network, while the blue hydrograph is produced with a GARR product that is customized for the client and created operationally with multi-agency rain gauge networks integrated with USNWS NEXRAD to produce an operational near-real-time (NRT) biascorrected hydrometeorological forcing for distributed model input. The light blue streaks are the hydrographs progressively generated with rainfall known at the time. The net result of these intermediate hydrographs when viewed for the totality of the storm duration, is a progression of hydrographs that when combined, produce the final hydrograph result (dark blue). 


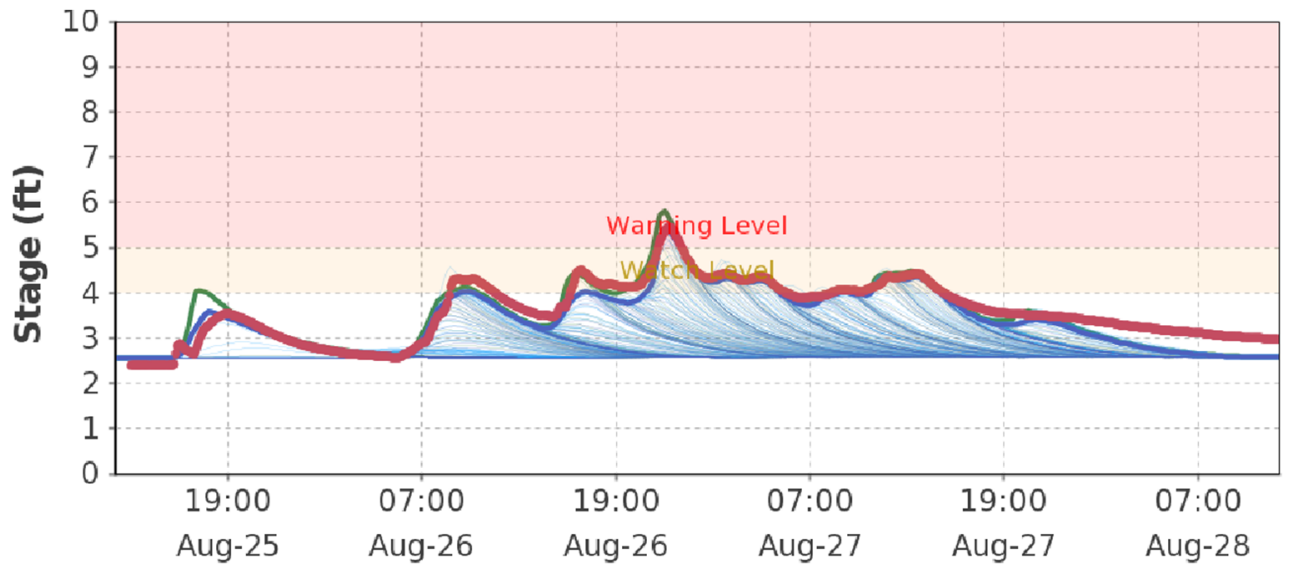

Figure 6: Results of Hurricane Harvey after travelling inland from the Gulf Coast with diminished strength but still produced flooding above flood stage during Harvey $(1 \mathrm{ft}=0.3048 \mathrm{~m}$ referenced to local channel bottom $)$.

\section{SUMMARY}

Managing flood emergencies with the aid of an EWS is becoming more widely adopted. Because heavy rainfall and flooding are affecting more people and infrastructure, organizations are turning to an EWS such as the COP described herein to help anticipate, effectively respond, and manage post-flood recovery. From a gap analysis, solutions were identified for development of the COP that delivers predictive flood information in near realtime to operational personnel. To accomplish objectives, NRT radar and rain gauge inputs are used for predictive modelling of depth and flow hydrographs at many locations through urban and peri-urban watersheds affecting a flooding. From modelled and observed data, predictive inundation maps and alert notifications are generated and mapped. This provides context and situational awareness during flood emergencies. Rules written by the end-user help capture experience and institutional knowledge, thus improving system effectiveness. After-Action reporting is facilitated through automated summaries of rainfall total images and values, road closures, rules triggered during the event, and tabulation of preliminary flood damages from flood levels estimated above finished floor elevations. Integration of data and information from multiple computer systems, cloud-hosting of the system provides high availability to agency personnel within a single interface. The COP solution has been operational since 2016 and continues to help everyone keep on the same page during flood emergencies.

\section{REFERENCES}

[1] Vieux, B.E., Smith, R.L. \& Vieux, J.E., When water becomes a hazard: A common operating picture helps keep everyone on the same page. 92nd Annual Water Environment Federation's Technical Exhibition and Conference, WEFTEC, 2019.

[2] Ahmadalipour, A. \& Moradkhani, H., A data-driven analysis of flash flood hazard, fatalities, and damages over the CONUS during 1996-2017. Journal of Hydrology, 578, p. 124106, 2019. 
[3] UNISDR (United Nations International Strategy for Disaster Reduction), Sendai Framework for Disaster Risk Reduction 2015-2030, 2015. www.wcdrr.org/uploads/ Sendai_Framework_for_Disaster_Risk_Reduction_2015-2030.pdf. Accessed 11 May 2015.

[4] Parker, D.J., Flood warning systems and their performance. Oxford Research Encyclopaedia of Natural Hazard Science, 2017.

[5] Terti, G., Ruin, I., Anquetin, S. \& Gourley, J.J., A situation-based analysis of flash flood fatalities in the United States. Bulletin of the American Meteorological Society, 98(2), pp. 333-345, 2017.

[6] Bodoque, J.M. et al., Improvement of resilience of urban areas by integrating social perception in flash-flood risk management. Journal of Hydrology, 541, pp. 665-676, 2016.

[7] Morss, R.E., Mulder, K.J., Lazo, J.K. \& Demuth, J.L., How do people perceive, understand, and anticipate responding to flash flood risks and warnings? Results from a public survey in Boulder, Colorado, USA. Journal of Hydrology, 541, pp. 649-664, 2016.

[8] Vieux, B.E., Janek, S. \& Vieux, J.E., How one community uses radar hydrology to cope with flooding: The city of Austin's flood early warning system. 27th Conference on Hydrology, Annual Meeting of the American Meteorological Society, 2013.

[9] Greene, P.S. et al., Urban flooding and climate change: Visualizing the impacts. Research Report, 2015. http://eos.ou.edu/hazards/urbanflooding/.

[10] Thielen, J., Bartholmes, J., Ramos, M.-H. \& de Roo, A., The European flood alert system: Part 1 - Concept and development. Hydrology and Earth System Sciences Discussions, European Geosciences Union, 5(1), pp. 257-287, 2008.

[11] Corral, C., Berenguer, M., Sempere-Torres, D., Poletti, L., Silvestro, F. \& Rebora, N., Comparison of two early warning systems for regional flash flood hazard forecasting. Journal of Hydrology, 572, pp. 603-619, 2019.

[12] Goniewicz, K. \& Burkle, F.M., Disaster early warning systems: The potential role and limitations of emerging text and data messaging mitigation capabilities. Disaster Medicine and Public Health Preparedness, 13(4), pp. 709-712, 2019.

[13] Llort, X., Sánchez-Diezma, R., Rodríguez, A., Sancho, D., Berenguer, M. \& SempereTorres, D., FloodAlert: A simplified radar-based EWS for urban flood warning. Hydroinformatics HIC, New York, 17-21 Aug. 2014.

[14] Hofmann, J. \& Schüttrumpf, H., Risk-based early warning system for pluvial flash floods: Approaches and foundations. Geosciences, 9(3), p. 127, 2019.

[15] Molina, L.E.T., Floods forecast in the Caribbean. Flood Risk Management, p. 55, 2017.

[16] Cosgrove, B. et al., An overview of the National Weather Service national water model. AGUFM, pp. H42B-05, 2016.

[17] Kim, J., Read, L., Johnson, L.E., Gochis, D., Cifelli, R. \& Han, H., An experiment on reservoir representation schemes to improve hydrologic prediction: coupling the National Water Model with the HEC-ResSim. Hydrological Sciences Journal, pp. 1$15,2020$.

[18] Acosta-Coll, M., Ballester-Merelo, F., Martinez-Peiró, M. \& la Hoz-Franco, D., Realtime early warning system design for pluvial flash floods: A review. Sensors, 18(7), p. 2255, 2018.

[19] Bedient, P.B., Huber, W.C. \& Vieux, B.E., Hydrology and Floodplain Analysis, 6th ed., Prentice-Hall: Saddle River, NJ, 2018. 
[20] Bandaragoda, C., Tarboton, D.G. \& Woods, R., Application of TOPNET in the distributed model intercomparison project. Journal of Hydrology, 298(1-4), pp. 178201, 2004.

[21] Beven, K., 14 Distributed models and uncertainty in flood risk management. Flood Risk Science and Management, p. 291, 2011.

[22] Looper, J.P. \& Vieux, B.E., An assessment of distributed flash flood forecasting accuracy using radar and rain gauge input for a physics-based distributed hydrologic model. Journal of Hydrology, 412, pp. 114-132, 2012.

[23] Vieux, B.E., Imgarten, J.M., Looper, J.P. \& Bedient, P.B., Radar-based flood forecasting: Quantifying hydrologic prediction uncertainty in urban-scale catchments for CASA radar deployment. World Environmental and Water Resources Congress 2008, Ahupua'A, pp. 1-10, 2008.

[24] Looper, J., Vieux, B. \& Moreno, M.A., Evaluating precipitation uncertainties using the Vflo hydrologic model. 23rd Conference on Hydrology, American Meteorological Society 2009 Annual Meeting, ASCE, Reston, VA, Jan. 2009.

[25] Vieux, B. \& Vieux, J., In pursuit of reliable flood prediction. Flood Risk Management and Response, p. 220, 2016.

[26] Worthington, T.A., Brewer, S.K., Vieux, B. \& Kennen, J., The accuracy of ecological flow metrics derived using a physics-based distributed rainfall-runoff model in the Great Plains, USA. Ecohydrology, 12(5), 2019.

[27] Berthet, L., Piotte, O., Gaume, É., Marty, R. \& Ardilouze, C., Operational forecast uncertainty assessment for better information to stakeholders and crisis managers. E3S Web of Conferences, 7, p. 18005, 2016.

[28] Vieux, B.E., Case studies in distributed hydrology. Distributed Hydrologic Modelling Using GIS, Springer: Dordrecht, pp. 211-234, 2016. 